\title{
Insulin and gall stones: a population case control study in southern Italy
}

\author{
G Misciagna, V Guerra, A Di Leo, M Correale, M Trevisan
}

Laboratorio di Epidemiologia, IRCCS "S de Bellis", Ospedale

Gastroenterologico, Castellana, Bari, Italy G Misciagna

V Guerra

Laboratorio di Biochimica, IRCCS "S de Bellis", Ospedale Gastroenterologico, Castellana, Bari, Italy A Di Leo

M Correale

Department of Social and Preventive Medicine, School of Medicine and Biomedical Sciences, State University of New York at Buffalo, Buffalo, New York, USA

M Trevisan

Correspondence to: Professor M Trevisan, Department of Social and Preventive Medicine, School of Medicine and Biomedical Sciences, 270 Farber Hall, 3435 Main Street, Buffalo, New York 14214-3000, USA. Email:

trevisan@buffalo.edu

Accepted for publication 8 February 2000

\begin{abstract}
Background-Hyperinsulinaemia has been associated with many common diseases in developed countries, such as ischaemic heart disease and colon cancer. Gall stones are also very prevalent in these countries but little is known about the association between insulin and gall stones.

Aims-To study the relationships between insulin and the incidence of gall stones in a sample of the general population.

Subjects and methods-Between May 1985 and June 1986, systematic sampling from the electoral register of Castellana, a small town in southern Italy, yielded 2472 subjects who had their gall bladder checked for gall stones by ultrasonography. Between May 1992 and June 1993, 1962 of the 2235 subjects without gall stones at the first examination agreed to a further ultrasound examination. A total of 101 subjects with newly diagnosed gall stones and 303 randomly chosen controls entered the study. Serum insulin was determined by radioimmunoassay, and concentrations of cholesterol, cholesterol high density lipoprotein (HDL), glucose, and triglycerides by standard enzymatic colorimetric methods. Unconditional multiple logistic regression was used to study the association between insulin and gall stones, controlling for the most common confounding factors.
\end{abstract}

Results-In individuals with no clinical diagnosis of diabetes and serum glucose $<7 \mathrm{mmol} / 1$, insulin was associated with gall stones. This association persisted even after controlling for sex, age, body mass index, and serum glucose. The risk of gall stones in the highest quintile of serum insulin was 2.66 (95\% confidence interval $1.04-6.72 ; \chi^{2}$ test for trend, $\left.p=0.03\right)$. The association of insulin with gall stones persisted when total and HDL cholesterol were entered in the logistic regression models, and only slightly decreased when serum triglycerides were included in the model.

Conclusions-The results of the study indicate that hyperinsulinaemia may play an important role in the aetiology of gall stones even in individuals without diabetes and with normal serum glucose levels.

(Gut 2000;47:144-147)

Keywords: gallstones; insulin; epidemiology; case control study
Hyperinsulinaemia and insulin resistance are thought to be important aetiological factors in many diseases of Western developed societies, such as ischaemic heart disease and colon cancer. ${ }^{1-4}$ Gall stones are common in Western developed societies ${ }^{5}$ but it is still uncertain if hyperinsulinaemia is a risk factor for the development of gall stones.

Previous existing epidemiological studies on insulin and gall stones ${ }^{6-14}$ were conducted in subjects with gall stones, and therefore exposure to insulin at the time of stone formation may have been different from insulin levels found at the time of diagnosis of gall stone disease. Furthermore, in all studies the cases were of symptomatic gall stones, and the symptom of the disease (biliary colic) could have caused dietary changes from fats to carbohydrates to decrease the stimulus for gall bladder contraction, ${ }^{15}$ so increasing the level of insulin in the blood. Finally, many studies found a positive association between insulin and gall stones in individuals with non-insulin dependent diabetes mellitus (NIDDM) with and without gall stones, ${ }^{10-12} 14$ but whether this association is present in non-diabetics remains to be confirmed.

This case control study was conducted in individuals from the general population who developed gall stones and who were screened 6-7 years before and found to be free of gall stones. In addition, only a small percentage $(6 \%)$ of cases reported having biliary colic. Multivariate analyses were confined to participants without a medical history of diabetes and with serum glucose $<7 \mathrm{mmol} / \mathrm{l}$.

\section{Subjects and methods}

Between May 1985 and June 1986, 3500 individuals (2000 men, 1500 women) aged 30-69 years, were selected by systematic sampling from the electoral register of Castellana, a town in southern Italy. ${ }^{16}$ After three invitations, 2472 subjects (1429 men, 1043 women) participated in the study $(70.6 \%$ response rate). The respondents answered a standard questionnaire, and a blood sample was taken in the morning following at least a 12 hour fast. Gall bladder ultrasonography was performed by two trained operators unaware of the subject's history, whose approach had previously been standardised in a specific study. ${ }^{17}$ Gall stones were defined as mobile echoes in the gall bladder lumen and cases of cholecystectomy as individuals without a gall bladder at ultrasound

Abbreviations used in this paper: HDL, high density lipoprotein; NIDDM, non-insulin dependent diabetes mellitus; BMI, body mass index. 
Table 1 Means (SD) or proportions for variables in patients with gall stones and controls, stratified by sex

\begin{tabular}{|c|c|c|c|c|c|c|}
\hline & \multicolumn{3}{|l|}{ Males } & \multicolumn{3}{|l|}{ Females } \\
\hline & Cases $(n=54)$ & Controls $(n=162)$ & $p$ Value $^{\star}$ & Cases $(n=47)$ & Controls $(n=141)$ & $p$ Value ${ }^{\star}$ \\
\hline Age & $59.74(10.75)$ & $54.06(10.61)$ & $<0.01$ & $58.83(10.84)$ & $53.99(10.01)$ & $<0.01$ \\
\hline $\mathrm{BMI}\left(\mathrm{kg} / \mathrm{m}^{2}\right)$ & $28.18(4.76)$ & $27.31(5.30)$ & 0.28 & $31.20(6.13)$ & $28.04(5.21)$ & $<0.01$ \\
\hline \multicolumn{7}{|l|}{ Diabetes } \\
\hline Medical history & $20.4 \%(5 \%)$ & $7.4 \%(2 \%)$ & $<0.01$ & $6.4 \%(4 \%)$ & $7.8 \%(2 \%)$ & 0.75 \\
\hline Medical history or glycaemia $\geqslant 7 \mathrm{mmol} / 1$ & $24.1 \%(6 \%)$ & $8.6 \%(2 \%)$ & $<0.01$ & $8.5 \%(4 \%)$ & $11.3 \%(3 \%)$ & 0.58 \\
\hline Glycaemia $(\mathrm{mmol} / \mathrm{l})$ & $6.18(2.42)$ & $5.78(1.78)$ & 0.19 & $5.58(1.38)$ & $5.42(1.40)$ & 0.51 \\
\hline Insulin $(\mu \mathrm{IU} / \mathrm{ml})$ & $8.50(7.22)$ & $7.08(6.01)$ & 0.16 & $9.62(7.00)$ & $6.64(5.55)$ & $<0.01$ \\
\hline Cholesterol $(\mathrm{mmol} / \mathrm{l})$ & $5.03(0.98)$ & $5.20(1.07)$ & 0.29 & $5.45(1.32)$ & $5.11(1.05)$ & 0.08 \\
\hline Cholesterol HDL (mmol/l) & $1.19(0.30)$ & $1.18(0.31)$ & 0.96 & $1.26(0.32)$ & $1.34(0.30)$ & 0.09 \\
\hline Triglycerides $(\mathrm{mmol} / \mathrm{l})^{\star \star}$ & $1.52(0.73)$ & $1.63(1.34)$ & 0.90 & $1.69(1.32)$ & $1.26(0.92)$ & $<0.01$ \\
\hline
\end{tabular}

${ }^{\star} t$ test for continuous variables, chi-square test for categorical variables.

${ }^{\star \star} t$ test on the natural logarithmic transformation of the raw values.

and with an abdominal scar. A total of 226 of 2472 subjects $(9.1 \%)$ had gall stones (92 men, 134 women). Between May 1992 and June 1993, 6-7 years later, subjects who had no gall stones at the first examination were invited for a second examination. A total of 1962 individuals (87.4\%) agreed to participate after three invitations. The same procedures were used, and the same personnel performed the second survey. After seven years, 104 of 1962 individuals who initially had no gall stones (55 men, 49 women) had developed gall stones at re-examination, an incidence of 7.9 per 1000 person-year. Only five of the 104 subjects with gall stones ( $4.8 \%$; four men, one woman) had been operated on for gall stones.

Ninety-nine subjects with gall stones and a gall bladder were offered a direct $x$ ray of the abdomen and cholecystography. Of the 79 subjects who agreed to have an $x$ ray, 70 had radiotransparent or mixed gall stones $(88.6 \%)$ and only nine had radio-opaque gall stones. Furthermore, only $6 \%$ of subjects with gall stones reported any episode of biliary colic. Three cases of gall stones were not considered in the study because there was not enough blood to analyse insulin, while controls without blood samples were replaced with new controls. Three controls for each case of gall stones were randomly chosen from the list of subjects without gall stones at the 1992-93 reexamination, frequency matched for sex with the cases so that 101 incident cases of gall stones and 303 controls entered the study. The variables included in the analyses were: gall stones (yes/no), serum insulin, body mass index (BMI), sex, age in years, serum glucose, cholesterol, cholesterol high density lipoprotein (HDL), and triglycerides. A diagnosis of diabetes was based on a physician's diagnosis (reported by the participant) or on a serum glucose value $\geqslant 7 \mathrm{mmol} / 1 .{ }^{18}$ Serum cholesterol,
HDL cholesterol, triglycerides, and glucose were analysed using standard enzymatic colorimetric methods (Boehringer Mannheim, Germany) under strict quality control.

Serum insulin was analysed using a radioimmunoassay kit (Diagnostic Systems Laboratories Inc., Webster, Texas, USA) with an intra-assay coefficient of variation of $6 \%$ and an interassay coefficient of variation of $7 \%$.

\section{STATISTICAL ANALYSIS}

Means (SD) or proportions were used as simple descriptive measures of the samples. The odds ratios and $95 \%$ confidence intervals (CI) of the odds ratio of gall stones by quintiles of insulin, serum glucose, and blood lipids, controlled for age, sex, and BMI (and also for glucose in the insulin case) were calculated using unconditional logistic regression. The backward method was used to select the variables significantly associated with gall stones in the final logistic regression model, forcing sex into the model, with a cut off for the likelihood ratio test at a $\mathrm{p}$ value $<0.10$.

Finally, the first order interactions of the variables with sex and age were evaluated. All statistical computations were made using STATA 4.0 Statistical Software (College Station, Texas, USA).

\section{Results}

In table 1, cases are compared with controls after stratification by sex. Cases of both sexes were on average older and had a higher BMI, and higher serum glucose, insulin, and triglyceride levels than controls. However, except for age, these differences were not statistically significant. The association between gall stones and BMI, insulin, and triglycerides was significant only in women. The prevalence of diabetes was significantly higher only in males

Table 2 Odds ratios (OR) and 95\% confidence interval of gall stones ${ }^{*}$ in the quintiles of serum lipids, insulin, and fasting serum glucose in subjects with no medical history of diabetes and fasting serum glucose $<7$ mmol/l (cases, $n=84 ;$ controls, $n=271$ )

\begin{tabular}{lllllll}
\hline & OR $(95 \% C I)$ & OR $(95 \% C I)$ & OR $(95 \% C I)$ & OR $(95 \%$ CI $)$ & $p$ Value & $p$ Value ${ }^{\star \star \star}$ \\
\hline Insulin & $1.13(0.47-2.73)$ & $1.58(0.67-3.73)$ & $1.60(0.66-3.89)$ & $2.64(1.04-6.72)$ & 0.28 & 0.03 \\
Glucose & $1.35(0.64-2.84)$ & $0.64(0.28-1.47)$ & $0.64(0.28-1.47)$ & $1.41(0.56-3.52)$ & 0.16 & 0.72 \\
Cholesterol & $0.91(0.41-2.05)$ & $0.98(0.44-2.19)$ & $0.64(0.28-1.48)$ & $0.83(0.37-1.88)$ & 0.83 & 0.95 \\
Cholesterol HDL & $0.77(0.36-1.66)$ & $0.54(0.24-1.22)$ & $0.41(0.18-0.96)$ & $0.66(0.29-1.47)$ & 0.28 & 0.19 \\
Triglycerides & $2.47(1.03-5.92)$ & $1.61(0.62-4.18)$ & $2.84(1.15-7.00)$ & $2.94(1.17-7.36)$ & 0.08 & $0.35 \dagger$ \\
\hline
\end{tabular}

${ }_{\star}^{\star}$ Controlling for age, sex and BMI. Insulin controlled also for serum glucose.

$\star \star$ Likelihood ratio test for heterogeneity.

$\star \star \star$ Likelihood ratio test for trend.

tLikelihood ratio test for trend on the natural logarithmic transformation of the raw values. 
Table 3 Coefficients $(\beta)$, standard error of the coefficients $(S E(\beta))$, p values (Wald test), odds ratio (OR), and $95 \%$ confidence interval of the odds ratio $\left(95 \%\right.$ CI) of the most parsimonious ${ }^{\star}$ unconditional multiple logistic regression model of the risk of gall stones for the variables studied. All variables were entered together in the same equation, and only subjects with no history of diabetes and fasting serum glucose $<7$ mol/l were considered (cases, $n=84$; controls, $n=271$ )

\begin{tabular}{lllllll}
\hline & Coefficient $(\beta)$ & $S E$ & Wald $\chi^{2}$ & p Value & Odds ratio & $95 \%$ CI \\
\hline Intercept & -2.91 & 1.48 & - & - & - & - \\
Sex $(0 \mathrm{M} / 1 \mathrm{~F})$ & -2.91 & 1.38 & -2.11 & 0.04 & 0.06 & $(0.01-0.81)$ \\
Age $(\mathrm{y})$ & 0.04 & 0.01 & 3.22 & $<0.01$ & 1.04 & $(1.02-1.07)$ \\
$\mathrm{BMI}\left(\mathrm{kg} / \mathrm{m}^{2}\right)$ & 0.05 & 0.03 & 2.12 & 0.03 & 1.05 & $(1.01-1.11)$ \\
Insulin $(\mu \mathrm{IU} / \mathrm{ml})$ & 0.04 & 0.03 & 1.74 & 0.08 & 1.04 & $(0.99-1.10)$ \\
Triglycerides $(\mathrm{mmol} / \mathrm{l}) \star \star$ & 0.54 & 0.29 & 1.85 & 0.06 & 1.72 & $(0.97-3.05)$ \\
Cholesterol $(\mathrm{mmol} / \mathrm{l})$ & -0.51 & 0.22 & -2.28 & 0.02 & 0.60 & $(0.39-0.93)$ \\
Sex $\times$ cholesterol (interaction term) & 0.61 & 0.26 & 2.32 & 0.02 & 1.84 & $(1.01-3.09)$ \\
\hline
\end{tabular}

${ }^{\star}$ Fasting serum glucose and cholesterol HDL are not in the model because they are not statistically significant at $\mathrm{p}<0.10$.

$\star \star$ Natural logarithmic transformation of the raw values.

compared with their respective controls, while serum total cholesterol was significantly higher and HDL cholesterol significantly lower only in female cases.

Table 2 reports the odds ratios of gall stones in the quintiles of serum insulin, glucose, and lipids, controlling for age, sex, and BMI (and also for glucose in the insulin cases), together with $\mathrm{p}$ values of the likelihood ratio tests for trend and heterogeneity. These analyses are limited to participants without diabetes and with serum glucose $<7 \mathrm{mmol} / \mathrm{l}$. Only insulin and triglycerides (normalised using natural logarithmic transformation) showed a statistically significant test for trend (likelihood ratio test $\chi^{2}$ distribution, $\mathrm{p}<0.10$ ), with the highest risk of gall stones in the highest quintiles of these variables.

Table 3 summarises the results of the multiple logistic regression analyses (most parsimonious unconditional model) performed in participants without a clinical diagnosis of diabetes and with fasting serum glucose $<7 \mathrm{mmol} / \mathrm{l}$. It should be noted that the results for insulin are for raw (non-transformed) values. This was done to more easily interpret the results (coefficient) of the logistic regression and because the level of significance was very similar for raw and log transformed variables. Insulin together with age, BMI, and triglycerides were independently and positively associated with gall stone risk. There was a statistically significant interaction between sex and serum cholesterol, with a positive correlation between gall stones and increasing cholesterol in women, whereas in men the effect was small and in the opposite direction. Insulin was correlated with both BMI and triglycerides. When triglycerides were eliminated from the model (data not shown), the association between insulin and gall stones was statistically significant at a $\mathrm{p}$ value of 0.03 , even if the point estimation of the odds ratio of gall stones for unit of insulin remained almost unchanged (the same was true for triglycerides when insulin was eliminated from the model). When BMI was eliminated from the model, the association between insulin and gall stones was statistically significant at a $p$ value $<0.01$, and the point estimation of the odds ratio of gall stones for unit of insulin increased for 1.04 to 1.07 , while the contribution of triglycerides to the risk of gall stones remained unchanged.

\section{Discussion}

The results of this population case control study demonstrated that individuals with gall stones had higher insulin levels than controls without the disease, after controlling for the most common confounding factors of the association: sex, age, BMI, and also for serum glucose and lipids. Furthermore, triglycerides were positively associated with gall stones and there was an interaction of cholesterol with sex: the association between gall stones and serum cholesterol was significantly stronger in women compared with men. All control and gall stone cases did not have a clinical diagnosis of diabetes and had serum glucose levels less than $7 \mathrm{mmol} / \mathrm{l}$ (the new cut off point established for diabetes in epidemiological studies at the population level). ${ }^{18}$ Subjects with gall stones were new cases identified at ultrasound from a cohort of subjects who had their gall bladder screened for gall stones by ultrasound 6-7 years previously. This cohort was a random sample of the population aged 30-69 years of a town in southern Italy. Only $6 \%$ of all subjects with gall stones had biliary colic, the only symptom associated with gall stones, ${ }^{19}$ and therefore it is highly improbable that a change in diet from lipids to carbohydrate, caused by the colic, could have determined the higher insulin levels in cases compared with controls.

The results of this study show that hyperinsulinaemia is associated with gall stones, not only in NIDDM $^{10-12}$ but also in subjects without a clinical diagnosis of diabetes and with serum glucose levels less than $7 \mathrm{mmol} / \mathrm{l}$. The well known association between NIDDM and gall stones ${ }^{20}{ }^{21}$ has been attributed to insulin resistance, but there are only a few studies on the relationship between insulin and gall stones. Norton et al in $1968^{6}$ found that insulin was normal or elevated in 13 cholecystectomised patients sampled from a file of 240 cholecystectomised patients (although two had diabetes mellitus and 10 were overweight). Stout et al in $1978^{7}$ studied 100 consecutive non-diabetic patients undergoing cholecystography for suspicion of gall bladder disease. The average level of insulin was higher in 19 individuals with gall stones compared with the 81 participants with no gall stones, but the results were not statistically significant at the chosen cut off $\mathrm{p}$ value of 0.05 . Thornton et al in $1978^{22}$ did not find any correlation between the biliary cholesterol saturation index and insulin 
in 25 healthy normal weight women. Scragg et al in $1984,{ }^{8}$ in a case control study comparing 173 individuals with prevalent gall stones and 284 hospital controls, found that insulin was associated with an increased risk of gall stones both in men and women independent of triglycerides, but he did not exclude diabetics from the study. Schwille et al in $1984^{9}$ did not find any association between insulin and gall stones in a case control study comparing 37 cases with 27 controls. Caroli et al in $1988,{ }^{10}$ Pazzi et al in 1988, ${ }^{12}$ and Laakso et al in $1990^{11}$ found that insulin was higher in diabetics with gall stones than in diabetics without gall stones after controlling for sex, age, BMI, and fasting glucose. Haffner et al however ${ }^{14}$ did not find a significant association between gall stones and insulin in 425 diabetics, 108 of whom had gall stones. As indicated, all of these studies were conducted in diabetics and therefore may not be useful in clarifying the role of insulin in the aetiology of gall stones in subjects without diabetes.

Haffner and colleagues, ${ }^{13}$ in a survey of 1250 men and 1616 women from a MexicanAmerican and non-Hispanic white population, found that in non-diabetic women, fasting insulin was significantly associated with the prevalence of gall bladder disease (assessed by self report) in a univariate analysis but not in a multivariate analysis adjusting for age, BMI, and other variables. ${ }^{13}$ Insulin concentration continued to be positively associated with gall bladder disease although this difference was no longer statistically significant. Kono and colleagues ${ }^{23}$ and more recently De Sanctis and colleagues $^{24}$ found that prevalent cases of gall stones were associated with reduced tolerance to glucose.

From a biological point of view, insulin may be linked with gall stones through stimulation of cholesterol synthesis. Bennion and Grundy ${ }^{25}$ in a study of cholesterol metabolism in Pima Indians with adult onset NIDDM found that gall bladder bile was significantly more saturated with cholesterol during insulin treatment than during uncontrolled hyperglycaemia. Another explanation for the association between hyperinsulinaemia and gall stones may be that individuals with gall stones are overweight or have a different distribution of body fat from controls. In this study, we controlled for BMI using multiple logistic regression but we did not measure the distribution of body fat and so were unable to control for this. However, while the distribution of body fat is associated with hyperinsulinaemia ${ }^{26}$ it does not seem to be associated with gall stones. ${ }^{27}$ In this study, insulin was also a risk factor for gall stones independent of triglycerides, even if triglycerides could be an intermediate between insulin and gall stones, because insulin stimulates the synthesis of triglycerides. ${ }^{27}$

In summary, the results of this study showed that hyperinsulinaemia was associated with gall stone formation in subjects without a clinical diagnosis of diabetes and with normal serum glucose, and that insulin metabolism may play an important role in many chronic diseases of the industrialised world. In our study the relation between insulin and gall stones appeared to be reduced when serum triglycerides were included in the model. The relationship between serum insulin and triglycerides is well established and underlies the close physiological link between these two variables (that is, triglyceride synthesis is stimulated by insulin). Therefore, the reduction in the level of significance of each of these variables when both are included in the model should be interpreted as an indication of the close physiological link that these two variables may have in the aetiology of gall stones.

1 Reaven GM. Role of insulin resistance in human disease. Diabetes 1988;37:1595-607.

2 Ferrannini E, Haffner SM, Mitchell BD, et al. Hyperinsulinemia: the key feature of cardiovascular and metabolic syndrome. Diabetologia 1991;34:416-22.

3 Gray RS, Fabsitz RR, Cowan LD, et al. Risk factors clustering in the insulin resistance syndrome. The Strong Heart Study. Am 7 Epidemiol 1998;148:869-78.

4 Giovannucci E. Insulin and colon cancer. Cancer Causes Control 1995;6:164-79.

5 Nakayama F. Cholelithiasis: causes and treatment. Tokyo: Igaku Shoin, 1997:11-26.

6 Norton JJ, Smith LR, Hamper E. Diabetes mellitus and gallstones with special reference to insulin assay. Am f Gastroenterol 1968;50:214-20.

7 Stout RW, Balmer JP, Henry RW, et al. Plasma lipids and gastro-intestinal hormones in subjects with gallstones. gastro-intestinal hormones in
Horm Metab Res 1978; 10:357-8.

8 Scragg RKR, Calvert GD, Oliver JR. Plasma lipids and insulin in gallstone disease: a case-control study. $B M \mathcal{F}$ 984;289:521-5.

9 Schwille PO, Hanisch E, Engelhardt W, et al. Basal plasma somatostatin in biliary stone patients. Klin Wochenschr 1984;62:595-7

10 Caroli A, Sardeo P, Gasparoni P, et al. Rapporti tra insulina plasmatica e calcolosi biliare nel paziente diabetico. Minerva Dietol Gastroenterol 1988;34:205-8.

11 Laakso M, Suhonen M, Julkunen R, et al. Plasma insulin, serum lipids and lipoproteins in gallstone disease in non-insulin dependent diabetic subjects: a case control study. Gut 1990;31:344-7.

12 Pazzi P, Trevisani L, Sartori S. Diabetes and cholelithiasis. Gut 1991;32:1422-3.

13 Haffner SM, Diehl AK, Mitchell BD, et al. Increased prevalence of clinical gallbladder disease in subjects with non-insulin-dependent diabetes mellitus. Am $\mathcal{f}$ Epidemiol 1990;132:327-35.

14 Haffner SM, Diehl AK, Valdez R, et al. Clinical gallbladder disease in NIDDM subjects. Relationship to duration of diabetes and severity of glycemia. Diabetes Care 1993;16: 1276-83

15 Froehlich F, Gonven JJ, Fried M. Role of nutrient fat and cholecystokinin in regulation of gallbladder emptying in men. Dig Dis Sci 1995;40:528-33.

16 Misciagna G, Leoci C, Elba S, et al. The epidemiology of cholelithiasis in southern Italy. Eur $\mathcal{F}$ Gastroenterol Hepatol 1994;6:937-41.

17 Festi D, Lalloni L, Taroni F, et al. Inter- and intra-observer variation in ultrasonographic detection of gallstones: the Multicentre Italian Study on the Epidemiology of Cholelithiasis (MICOL). Eur f Epidemiol 1989;5:51-7.

18 The expert committee on the diagnosis and classification of diabetes mellitus. Report of the expert committee on the diagnosis and classification of diabetes mellitus. Diabetes Care 1997;20:1183-97.

19 Barbara L, Sama C, Morselli Labate AM, et al. A population study on the prevalence of gallstone disease: the Sirmione study. Hepatology 1987;7:913-17.

20 Nakayama F. Cholelithiasis: causes and treatment. Tokyo: Igaku Shoin, 1997;109-11.

21 Misciagna G, Leoci C, Guerra V, et al. Epidemiology of cholelithiasis in Southern Italy. Part II: Risk factors. Eur $\mathcal{F}$ Gastroenterol Hepatol 1996;8:585-93.

22 Thornton JR, Heaton KW, MacFarlane DG. Plasma lipids, insulin and gallstone risk. Clin Sci 1978;59:831-2.

23 Kono S, Shinchi K, Ikeda N, et al. Prevalence of gallstone disease in relation to smoking, alcohol use, obesity, and glucose tolerance: a study of self-defense officials in Japan. Am f Epidemiol 1992;136:787-94.

24 De Santis A, Attili AF, Corradini SG, et al. Gallstones and diabetes: a case-control study in a free-living population diabetes: a case-control study in a
sample. Hepatology 1997;25:787-90.

25 Bennion LJ, Grundy SM. Effects of diabetes mellitus on cholesterol metabolism in man. $N$ Engl f Med 1977;296: 1365-71.

26 Bjorntorp P. Abdominal obesity and the metabolic syndrome. Ann Med 1992;24:465-8.

27 Haffner SM, Diehl AK, Stern MP, et al. Central adiposity and gallbladder disease in Mexican Americans. Am $\mathcal{F}$ Epidemiol 1989;129:587-95. 